\title{
Orphan Status may be Protective Factor Against Severe Toxicity of HIV Therapy in Children from Resource-limited Settings (Case report)
}

L. Hoin (Leang Hoin)', M. Palun (Miroslav Palun)', A. Gallo (Andrea Gallo)', V. Sladeckova (Veronika Sladeckova)', B. Durcova (Barbora Durcova)', J. Benca (Juraj Benca) $)^{3}$ L. Matulnikova (Ludmila Matulnikova)3) M. Sramkova (Maria Sramkova)', P. Cmorej (Patrik Cmorej)ํ. P. Vansac (Peter Vansac)'1, P. Haj Ali (Peri Haj Ali) $)^{1,2}$, E. Grey (Eva Grey) ${ }^{1}$

${ }^{1}$ House of Family, House of Hope, Phnom Penh, SEU Tropical Program,

Sihanoukville, $\mathrm{KH}$

${ }^{2}$ MPH Public Health Program, Kuala Lumpur, MY

${ }^{3}$ SEUC Health program, St. College, Nove Zamky, SK

\section{E-mail address:}

marankij@googlemail.com

\section{Reprint address:}

Leang Hoin

House of Family, House of Hope, Phnom Penh

Sihanoukville, $\mathrm{KH}$

Source: Clinical Social Work and Health Intervention

Pages: $71-73$
Volume: 9

Issue: 3

\section{Reviewers:}

Roberto Cauda - roberto.cauda@Unicatt.it

\section{Key words:}

Orphan status. HIV. HIV therapy toxicity.

\section{Publisher:}

International Society of Applied Preventive Medicine i-gap

CSWHI 2018; 9(3): 71 - 73; DOI 10.22359/cswhi_9_3_10 (c) 2018 Clinical Social Work and Health Intervention

\section{Abstract:}

Background: Orphan status is usually a risk factor for many diseases and results in social exclusion and worse outcomes than children with parents. 
Methods: The case reports of severe toxicity where death was averted by close monitoring in an orphanage in Phnom Penh, Cambodia are presented.

Results: Close monitoring of adherence of antiretroviral therapy (ARV) is possible only in close facility, e.g. orphanage, where regular DOT (directly observed therapy) and DOTOX (directly observed toxicity) is possible.

Conclusions: Three cases of severe toxicity: two bone marrow severe suppression and one cardiomyopathy are presented. Deaths were averted by close observation and early interventions.

\section{Introduction}

Children with HIV in resource-limited settings have much higher rates of orphanhood, malnutrition, and coexisting infections such as tuberculosis. Among these risk factors, orphan status deserves particular attention. About 14 million children have been orphaned due to HIV, $80 \%$ of these living in sub-Saharan Africa. Orphan status defines a child's social and economic outcomes. Several studies have reported worse outcomes for orphans, including poorer health and nutrition; higher hospitalization rates; lower school attendance; higher childhood mortality. In some studies from resource-limited settings, orphan status has been associated with ART non-adherence, however, other studies didn't confirm this. The particular system may play a role in this: one study suggests that orphans with institutional caregivers have better adherence than those with non-institutional caregivers. (Wachholz \& Ferreira, 2007) Monitoring of ARV toxicity may be easier in institutional care, where possibilities for further examinations are higher, especially when comparing to rural or street children.

Hereby, we present three cases where orphan status followed by indoor placement was actually a protective factor regarding ARV toxicity and saved lives.

\section{Case report 1}

A 16 year old girl presented with innate HIV infection. 10 years on 1 st line treatment (Zidovudine, 3TC, 4DDI) plus cotrimoxazole she had several episodes of anemia due to myelosuppression. Decreased physical activity and ability to play activated the examination and search for the cause of the problems. Cardiologic examination revealed severe cardiomyopathy due to AZT, which was immediately replaced.

\section{Case report 2}

A 12 year old girl presented with advanced AIDS as a late presenter. Therapy hag been AZT+3TC+4DDI, plus anti-TB treatment (RIF, INH, EMB, PZA). She was diagnosed with severe anemia, a drop of hemoglobin levels from 130 to 50 with depressed bone marrow activity. By coincidence the results were seen by a Doctor visiting the orphanage. A change of therapy brought her blood count back to normal levels.

\section{Case report 3}

A 6 year old boy with terminal stage of AIDS plus TBC was admitted from the street and put on 1st line ARV. A Social worker and volunteer observed decreased ability to play and decreased motoric performance, blood was tested and very severe anemia was found ( $\mathrm{Hb}$ level 30mg/l) and 
erythropoetin was administrated immediately, change of therapy was done as well.

\section{Conclusions}

In these cases, deaths from ARV toxicity were averted by careful monitoring in institutional care by trained Social Workers, volunteers and medical personnel. In ARV toxicity, earlier interventions save lives, therefore orphan status was a protective factor.

\section{References}

1. WACHHOLZ NI, FERREIRA J (2007) Adherence to antiretroviral therapy in children: a study of prevalence and associated factors. Cad Saude Publica. 2007;23 (Suppl 3):S424-S434.

2. SHAHUM A, KALAVSKAA, CHABADOVA M, KALAVSKY E, BENCA J, MRAZOVA M, POLONOVA J, TOMANEK P, OBTULOVIC M, DOBRODENKOVA S, SLADECKOVA V, BUJDOVA N, HRINDOVA T, MIKOLASOVA G, SLADICEKOVA R, HORAK P, DUDOVA Z, ADAMCOVA J, SPANIK S, KRCMERY V (2017) Quality of Life, Risk Factors and Mortality in Children with HIV/AIDS on 2nd Line Treatment, Slow Progressors and Late Presenters in Cambodian Orphanage. Clinical Social Work and Health Intervention. 8. 7-12. 10.22359/cswhi_8_2_01. 